\title{
Modeling Larval Dispersion of Rockfish: A Tool for Marine Reserve Design?
}

\author{
William T. Stockhausen
}

NOAA Fisheries, Alaska Fisheries Science Center, Seattle, Washington

\author{
Albert J. Hermann \\ NOAA Pacific Marine Environmental Laboratory, Seattle, Washington
}

\section{Abstract}

Marine reserves have been suggested as an important tool for rockfish management and conservation in the northeast Pacific Ocean. One issue confronting effective reserve design is to ensure that larvae released within a reserve system are not lost through dispersal but actually contribute to the population within the reserve areas and beyond. As a first attempt to address this issue for marine reserves in the Aleutian Islands (AI) and Gulf of Alaska (GOA), we modified the particle-tracking module of a three-dimensional circulation model for the northeast Pacific to incorporate simple larval behaviors such as diel vertical migration. We used the model to simulate dispersal of rockfish larvae during peak months of larval release from a suite of potential reserve locations in the AI and GOA. Because larval behavioral patterns are unknown for most rockfish species, we incorporated several alternative behavioral models in the simulations. We also addressed intra- and interannual variation in dispersal by repeating the simulations with larval release occurring during several different months for two different years. Model results indicate that retention of larvae near release sites is greatest for sites in the AI and least for sites in the GOA. However, we regard these results as preliminary and as a demonstration of the modeling approach rather than as an actual basis for selecting reserve areas. 


\section{Introduction}

Rockfishes (Sebastes spp.) represent one of the most diverse (over 70 species) and economically valuable multispecies resources for commercial and recreational fisheries along the Pacific coast of the United States and Canada (Love et al. 2002). Rockfish have been taken commercially since 1875 in California and since the early 1900s off Alaska. In Alaska waters, a large fishery for Pacific ocean perch (POP, Sebastes alutus) by the USSR and Japan developed in the early 1960s. Catches quickly peaked in the mid-1960s at nearly 500,000 t, but were followed by a precipitous decline at the end of the 1960s that continued into the next decade (Love et al. 2002). More recently, estimated stock abundance has rebounded to $\sim 50 \%$ of that in the early 1960 s, apparently due to a shift to environmental conditions that favor recruitment success (Heifetz et al. 1999, Ito et al. 1999, Hanselman et al. 2005, Spencer et al. 2005). Directed fisheries currently exist in Alaska for POP, northern rockfish (S. polyspinis), and dusky rockfish (S. ciliatus). All other rockfish species are considered nontarget species and can only be retained as certain percentages of the targeted species catch. Under current harvest strategies, no federally managed rockfish species in Alaska are considered to be overfished (NPFMC 2004a,b).

However, there is concern that existing harvest strategies for rockfishes may be inadequate (e.g., Clark 2002, Dorn 2002, Ianelli 2002, Berkeley et al. 2004). The life history characteristics of many rockfish species make individual stocks particularly vulnerable to overexploitation and slow to recover. In particular, many species mature slowly (age at 50\% maturity greater than 5-10 years) and are long-lived (50-150 years) (Love et al. 2002). Recruitment success can be exceedingly intermittent (Ralston and Howard 1995, Love et al. 2002). Further, at least some species show evidence of genetic divergence and stock structure on small spatial scales (Withler et al. 2001, Buonaccorsi et al. 2002, Matala et al. 2004).

Marine reserves (i.e., harvest refugia) have been suggested as an important tool for rockfish management and conservation in the Aleutian Islands (AI) and Gulf of Alaska (GOA), as well as along the West Coast of the United States (Murray et al. 1999, Soh et al. 2001, Berkeley et al. 2004). Potential advantages posited for the use of marine reserves in conjunction with existing harvest strategies include protection from stock depletion and prevention of serial overfishing of substocks (Soh et al. 2001), maintenance of complex population age and spatial structure (Berkeley et al. 2004), and conservation of essential fish habitat (O’Connell et al. 1998).

The criteria for designating areas as marine reserves depend on the management goals the reserves are intended to address. For reserves whose purpose is to protect a species from depletion, one element 
of effective design is to ensure that local populations protected in reserves are self-sustaining; that is, they remain viable in the absence of recruitment from outside the reserve system. Consequently, larvae released within the reserve system must not be completely lost through dispersal, but must contribute to the population within reserve areas as adults (Roberts 2000, Warner et al 2000). In this respect, areas that display a high degree of larval retention may be preferred as reserve sites to areas that have low larval retention.

As a demonstration of one approach to address the issue of larval retention for rockfish stocks in the AI and GOA, we coupled an individual-based model (IBM) that incorporated simple larval behaviors such as vertical migration to a three-dimensional circulation model for the northeast Pacific to assess the extent of local retention at potential sites of larval release. We used the model to simulate dispersal of rockfish larvae during peak months for larval release (i.e., parturition) from a suite of potential reserve locations in the AI and GOA. We addressed temporal variation in dispersal by simulating hydrodynamic currents for two different years and three different release periods within each year. Also, because larval behavioral patterns are uncertain for most rockfish species, we repeated model runs using several alternative behavioral models. Among the sites considered, we regarded release sites that exhibited strong retention patterns that were robust to variation in release period and larval behavior as the best candidates for reserve location. We regard the results presented here as a demonstration of the modeling approach and preliminary at best. They should not be used as the basis for reserve selection.

\section{Materials and methods}

The early life history of rockfishes in Alaska waters is generally characterized by a lack of species-specific information for most species, and information is sparse even for the best-studied species. Difficulty in identifying larval Sebastes to species level confounds understanding of species-specific patterns and behavior (Matarese et al. 2003). As such, our simulation model reflects an amalgam of details drawn from studies of disparate individual species or from early life history characteristics of rockfishes classified only to the generic level.

\section{Larval IBM}

We developed a very simple IBM for rockfish larval behavior that incorporated the ability to actively migrate vertically to occupy a preferred depth range. Modeled larvae that were outside their preferred depth range at any time immediately began to swim vertically (up or down) at a prescribed rate until they entered their preferred depth range. In the current IBM configuration, preferred depth ranges could differ between 
daytime and nighttime to model diel vertical migration, a type of active larval behavior that could result from feeding behaviors, light sensitivity, or predator avoidance but could also enable larvae to utilize vertical current shear to modify dispersal patterns from those of passive particles (Neilson and Perry 1990).

Unlike many marine fish species, rockfish do not undergo a planktonic egg stage. Rockfish are a primitive viviparous group, with females extruding larvae rather than eggs in a process known as "parturition" (Love et al. 2002). Extruded larvae are ready to begin feeding and, at 3-7 $\mathrm{mm}$ standard length, are comparable in size to first-feeding larvae of species with planktonic eggs (Kendall and Lenarz 1987). In Alaska waters, parturition occurs primarily during the spring and summer for most species (see references in Wyllie Echeverria 1987, Love et al. 2002). Depending on species, larvae may be released near the bottom or in midwater (Love et al. 2002). Recent studies of POP in British Columbia suggest that, for this species, adult females migrate to the mouths of submarine canyons and release their larvae at depth (500-700 m); the larvae subsequently remain at depth for a month or more prior to moving to shallower water (Love et al. 2002). However, most rockfish larvae are typically found above the pycnocline at relatively shallow depths (Ahlstrom 1959, Boehlert et al. 1985, Sakuma et al. 1999, Matarese et al. 2003). Matarese et al. (2003) give the duration of the larval stage as 1-2 months (see also Kendall and Lenarz 1987, Laidig et al 1991, Sakuma and Laidig 1995, Plaza Pasten et al. 2003). After completion of the larval stage following growth to $20-30 \mathrm{~mm} \mathrm{SL}$, most rockfish species undergo a pelagic juvenile stage lasting several weeks to months before transitioning to a demersal existence (Love et al. 2002).

Little is directly known of larval behavior of rockfish species in the AI and GOA. Studies that examined rockfish larvae focused on temporal patterns of larval abundance or on broad spatial patterns, not on vertical position or diel behavior (e.g., Doyle et al. 2002, Matarese et al. 2003). Complicating these studies is an inability to distinguish most rockfish larvae at the species level (Matarese et al. 2003). More work has been done along the west coast of North America. Ahlstrom (1959) found rockfish larvae off California and Baja California above or in the thermocline $(<100 \mathrm{~m})$ with no consistent day/night differences in vertical distribution. Barnett et al. (1984) and Moser and Boehlert (1991) obtained similar results off southern California. Boehlert et al. (1985) found Sebastes larvae off Oregon distributed from 5 to $40 \mathrm{~m}$ during the day and from the surface to $30 \mathrm{~m}$, as well as below $50 \mathrm{~m}$, at night. Shenker (1988) found rockfish larvae in the neuston off Oregon. Sakuma et al. (1999) found that postflexion rockfish larvae off central California were generally above the pycnocline. They found Sebastes spp. larvae most abundant between 20 and $40 \mathrm{~m}$, regardless of diel time period, although mean depth of capture was $40 \mathrm{~m}$; postflexion S. jordani were 
found somewhat deeper (mean depth of capture was 50-70 m). Sakuma et al. (1999) also found little evidence for diel vertical migration in postflexion Sebastes spp. or S. jordani larvae.

Thus, evidence from the west coast of North America suggests that rockfish larvae occupy the near-surface layers of the water column and do not migrate on a diel basis. However, the regional hydrography of the west coast is dominated by strong upwelling, whereas the GOA is dominated by downwelling (Ware and McFarlane 1989). Because local adaptations for successful recruitment may favor different behavioral strategies for larvae in the two regions, we regarded the vertical behavior of rockfish larvae in the GOA and AI as reasonably uncertain.

To address this perceived uncertainty in rockfish larval behavior, we considered three different behavioral scenarios in our models based on assumed depth preference:

1. "Near Surface" (NS);

2. "At Depth" (AD); and

3. "Vertical Migration" (VM).

Under the NS behavior, the preferred depth range for larvae was 5-20 m. Under the AD scenario, the preferred depth range was much deeper, at 80-100 m. The preferred depth range was static and did not change with time for these two scenarios. Under the VM scenario, larvae underwent diel vertical migration, preferring to be at depth $(80-100 \mathrm{~m})$ during the daytime but rising to near the surface at night $(5-20 \mathrm{~m})$. The NS and AD scenarios bracket the depth ranges over which rockfish larvae have been observed on the west coast; the NS scenario is probably closest to the truth.

\section{Larval release sites}

Direct information on areas of rockfish parturition in the AI and GOA is lacking. Thus, modeled larvae were released from locations that have been identified as areas of persistent, high abundance of rockfish species (Fig. 1). In the AI, areas were chosen that exhibited persistent aggregations of a complex of rockfish species (rougheye, S. aleutianus; shortraker, S. borealis; and POP) over multiple years in data from trawl surveys conducted tri- and biennially by the National Marine Fisheries Service (NMFS; Reuter and Spencer 2007). In the GOA, areas were chosen that exhibited persistently high fishery catches of northern rockfish (Clausen and Heifetz 2002). However, the trawl survey and the fishery are not temporally coincident with the period of peak parturition, so areas of high abundance identified from these data sources may not correspond to areas where parturition actually occurs. However, in lieu of more specific information, we assumed these areas broadly coincided with sites where parturition occurs. 


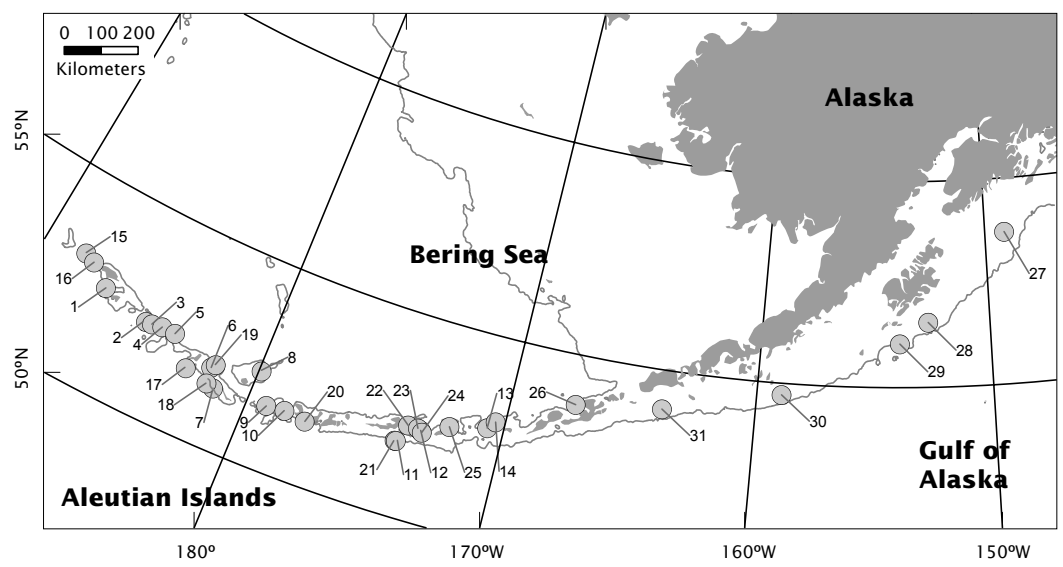

Figure 1. Locations of modeled larval release sites (circles). The 500 m isobath is also shown.

The timing of parturition at these sites was based on reported parturition dates summarized in Wyllie Echeverria (1987) and Love et al. (2002). Parturition occurs during April and May in the GOA for POP (Westrheim 1975 and Lyubimova 1965, cited in Wyllie Echeverria 1987). It occurs during April in British Columbia for shortraker and rougheye (Westrheim 1975 cited in Wyllie Echeverria 1987), and probably occurs somewhat later in the AI and GOA. Northern rockfish parturate throughout the spring (Love et al. 2002). As such, we considered larval release times of April-June in the model runs.

\section{Hydrodynamic model}

Dispersal of meroplanktonic larvae in the AI and GOA can be influenced by several large-scale current patterns, as well as smaller-scale gyres and eddies. The GOA is bounded to the east, north, and west by the mountainous coast of Alaska and is open to the south (Fig. 2). The bottom topography is complex, with many deep canyons intruding onto the continental shelf. Regional meteorology is dominated by strong storms, the frequency of which varies on seasonal to decadal timescales. These storms impact oceanic current patterns in the region. Circulation in the GOA is dominated by two current systems, the subarctic gyre in the ocean basin and the Alaska Coastal Current (ACC) on the continental shelf (Fig. 2; Stabeno et al. 2004). The subarctic gyre consists of the eastward-flowing West Wind Drift in the south, the northerly flowing Alaska Current to the east, and the southwestwardly flowing Alaskan Stream to the north. The latter flows at speeds up to $50 \mathrm{~cm}$ per s along the slope 


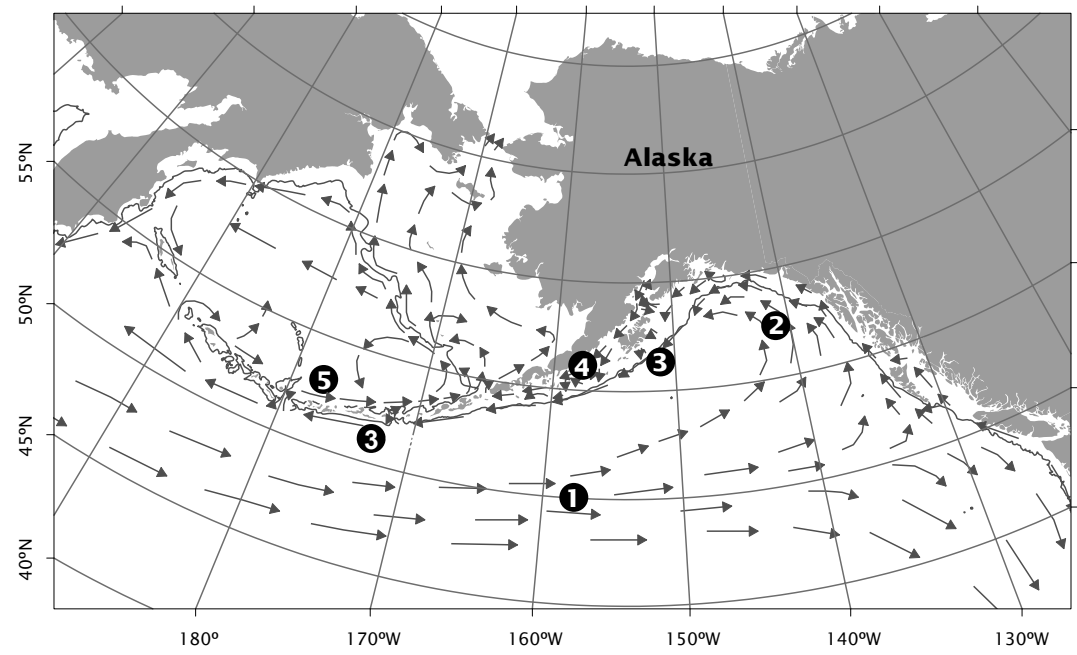

Figure 2. General current pattern near the Aleutian Islands and Gulf of Alaska. Major features include (1) the West Wind Drift, (2) the Alaska Current, (3) the Alaskan Stream, (4) the Alaska Coastal Current, and (5) the Aleutian North Slope Current. The 500 m isobath is also shown.

of the Alaska Peninsula and the AI (Reed and Stabeno 1989). The ACC is driven by winds and freshwater runoff and dominates circulation on the shelf (Stabeno et al. 1995).

To the west of the GOA, the AI and Aleutian Archipelago stretch over $2,000 \mathrm{~km}$ from the Alaska Peninsula west to the Commander Islands off the Kamchatka Peninsula in eastern Asia. Passes between the islands connect the North Pacific Ocean and the Bering Sea (Fig. 3). They vary from wide, deep channels bordered by small islands (e.g., Amchitka and Buldir Passes) to narrow, shallow channels between large islands (e.g., Unimak and Seguam Passes; Ladd et al. 2005). Flows in the passes are dominated by tides, and strong tidal currents mix the water column over the shallow sills (Stabeno et al. 2005). The shelf is generally narrow $(<10 \mathrm{~km})$ on the northern side of the islands; on the southern side, as one travels west, the shelf is initially wide $(\sim 100 \mathrm{~km})$ near the Alaska Peninsula, but narrows to $25 \mathrm{~km}$ at Samalga Pass (Hunt and Stabeno 2005). The Aleutians are affected by three major current patterns: the Alaskan Stream and the ACC flowing westward from the GOA along the southern side of the archipelago and the eastward-flowing Aleutian North Slope Current (ANSC) north of the islands from Amchitka Pass (Hunt and Stabeno 2005 and references therein). The inshore portion 


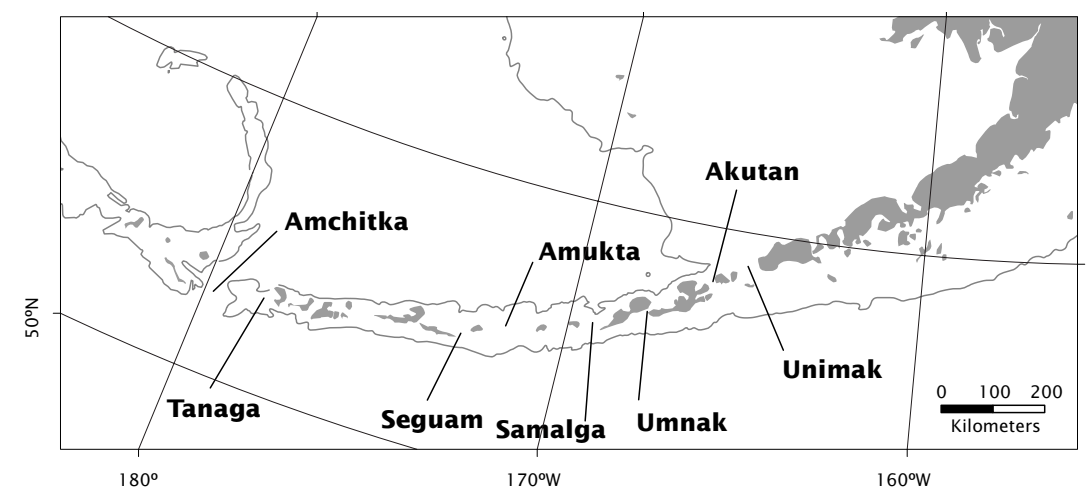

Figure 3. Major passes in the eastern and central Aleutian Islands. The $1,000 \mathrm{~m}$ isobath is also shown.

of the ACC enters Unimak Pass and flows into the southeast Bering Sea, while the offshore portion continues east to Samalga Pass before turning north through the pass to join the ANSC. The Alaskan Stream flows eastward along the shelf break to Amchitka Pass, where the archipelago turns to the northwest and the stream separates from the slope and broadens, resulting in the formation of eddies and meanders (Stabeno and Reed 1994).

The hydrodynamic model utilized in the study is part of a suite of basin-, regional-, and local-scale circulation models which are linked via one-way coupling (Curchitser et al. 2005; also see www.pmel.noaa. gov/people/dobbins/nep.html). These include a basin-scale model encompassing the North Pacific at 20-40 km resolution (NPac), a regional model at $\sim 10 \mathrm{~km}$ resolution spanning the Northeast Pacific (NEP; Fig. 4), and, finally, local models at $\sim 3 \mathrm{~km}$ resolution in regions of specific interest. One-way nesting of the models was implemented using a hybrid of nudging and radiation approaches, as described in Marchesiello et al. (2001).

The nested models utilize the Regional Ocean Modeling System (ROMS), a free-surface, hydrostatic primitive equation ocean circulation model. ROMS is a terrain-following, finite difference (Arakawa C-grid) model with the following advanced features: extensive restructuring for sustained performance on parallel computing platforms; high-order, weakly dissipative algorithms for tracer advection; a unified treatment of surface and bottom boundary layers, based on the Large et al. (1994; KPP) and Styles and Glenn (2000) algorithms; and an integrated set of procedures for data assimilation. The NEP version of ROMS also includes a Lagrangian particle tracking algorithm, which uses a fourth-order 


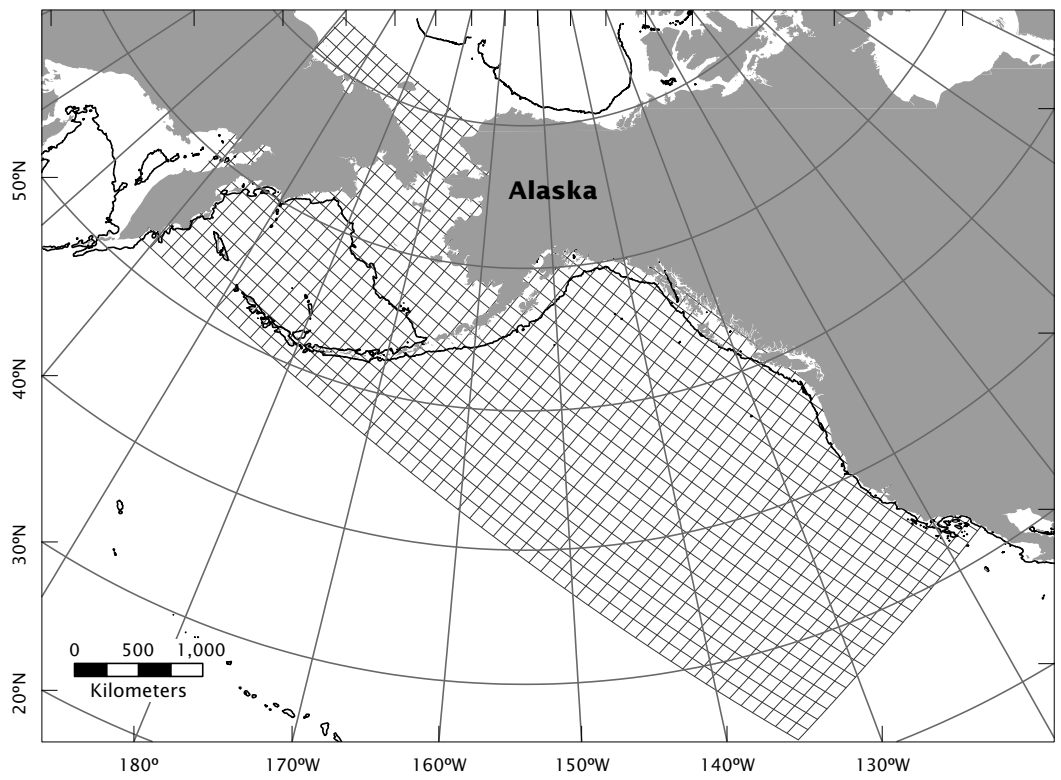

Figure 4. Extent of horizontal grid for the Northeast Pacific (NEP) threedimensional hydrodynamic model. Model grid spacing is $\sim 10 \mathrm{~km}$. Illustrated grid cells correspond to $10 \times 10$ model cells. The 500 m isobath is also shown.

predictor-corrector scheme to determine instantaneous positions for released passive particles. Numerical details for ROMS can be found in Haidvogel et al. (2000), Moore et al. (2004), and Shchepetkin and McWilliams (2005), as well as on the ROMS Web site (www.myroms. org/index.php).

Hindcasts of the nested circulation models were forced by atmospheric reanalysis products and data (NCEP, COADS, QuickScat), with freshwater runoff time series ( $T$. Royer, Old Dominion University, pers. comm.; also USGS data) applied to the NEP. Surface fluxes of heat and momentum were calculated from the atmospheric data using bulk formulae (Fairall et al. 1996), which include the instantaneous model sea surface temperature (SST). To reduce the computational burden, tidal forcing was not applied. Although formal validation of the NEP model has not yet been completed, the output reproduces the major current patterns in the northeast Pacific. It also captures the spatial and temporal characteristics of mesoscale features such as eddies and gyres in a statistical sense. 
For the present study, NEP model output was utilized to provide time-varying three-dimensional current fields in which to embed the larval IBMs. NEP model output consisted of 3-day averages of instantaneous model current fields. We enhanced an "offline" version of the ROMS Lagrangian particle tracking algorithm to incorporate the larval IBMs. This version was "offline" because it read in pre-computed flow fields rather than computing the flow fields simultaneous to tracking the IBMs. Because the flow fields were calculated only once, this approach substantially reduced computer memory and time requirements when different IBM scenarios were run using the same hydrodynamic scenario. In an informal test of the offline tracking algorithm, we found reasonable qualitative agreement between the tracks of real drifters deployed in the GOA in 1998 and 2001 and model drifters simulated over the same time frames.

\section{Model cases}

Each model run consisted of releasing 25 "larvae" in a small $5 \times 5$ grid at each of 31 release sites along the Aleutian Islands or in the Gulf of Alaska (Fig. 1). Once released, larvae acted as Lagrangian drifters embedded in the NEP circulation flow fields and were tracked for 60 model days. Larvae whose movement would have taken them beyond the model grid were flagged and were not tracked further. Since the duration of the larval stage is typically between 1 and 2 months for many rockfish species in the northeast Pacific Ocean (Matarese et al. 2003), we scored each larva as being retained near its release site if, at any time after 30 days following its release, it was within $50 \mathrm{~km}$ of that site. Larvae that left the grid were included in the scoring.

We conducted 18 model simulations in all. For each of the three larval behavior scenarios, we repeated model runs for release times at the beginning of the months of April, May, and June for two different years. NEP model output was available for 1996-2002; we haphazardly elected to use output for 1998 and 2001. Using only two years allowed us to incorporate some measure of interannual variability into our results, while not being computationally overburdensome (each model simulation took approximately 12 hours). To evaluate retention for each release site, we calculated the mean fraction of larvae retained near the site over the two model years and three within-year release times.

\section{Results}

\section{IBM tracks}

From the perspective of individual model larvae, the model results exhibited substantial complexity and variability with respect to larval behavior type, time of parturition with a year, and year of parturition (Figs. 5-7). Spatial patterns in individual tracks reflect the cumulative 
effect of complex current features predicted by the NEP hydrodynamic model. Numerous eddies and gyres are evident in the model currents near the Aleutian Islands, leading to larval tracks in the same area that exhibit numerous loops and whorls (e.g., those from site 23, NS case, Fig. 5). Somewhat larger-scale gyres are also predicted by the hydrodynamic model off the shelf in the GOA (e.g., as exhibited by tracks from site 27, NS case, Fig. 7), but not on the shelf where flow is dominated by the ACC (as exhibited by the tracks from sites 28 and 29, Fig. 7). The effects of the gyres appear to be greatest for larvae that prefer to remain near the surface (NS behavioral scenario), with lesser effects on larvae that prefer to remain at depth (AD scenario) or migrate on a diel basis (VM scenario).

Substantial variation in the tracks also occurred depending on the date of parturition. Larvae following the NS scenario that were released in April 1998 on the GOA shelf (sites 27-31) tended to move south off the shelf into deep water (Fig. 5). In contrast, larvae released in June 1998 from the same sites moved southwest along the shelf and into the AI (Fig. 6). Also, more larvae were advected into the Bering Sea along the $500 \mathrm{~m}$ isobath when released in June (Fig. 6) than in April (Fig. 5).

Finally, there was also substantial interannual variation in the tracks. Larvae released in the GOA in April 2001 tended to move along the shelf break to the southwest (Fig. 7), while those released in April 1998 from the same sites moved offshore more to the south (Fig. 5). More larvae were also advected into the Bering Sea in 2001 (Fig. 7) than in 1998 (Fig. 5).

\section{Larval retention}

Taking the modeled larvae in aggregate, the highest retention of larvae occurred in the western AI under all three behavioral scenarios at sites in the vicinity of Amchitka and Tanaga passes (Fig. 8). Conversely, the lowest retention occurred for sites in the GOA. The fraction of larvae retained at each site was generally highest under the AD scenario (mean of $27 \%$ retention among sites) and lowest under the NS behavioral scenario (17\%), while retention under the VM scenario was generally intermediate between the two (24\%). However, results at individual sites did not always follow this pattern (e.g., the easternmost site in the GOA, site 27 , had NS $>V M \approx A D$ ).

\section{Discussion}

To maximize the potential for long-term population persistence and sustainability, marine reserves should protect self-recruiting local populations-that is, local populations within the reserve should not have to rely on recruitment from beyond the reserve to remain in existence (Roberts 2000, Warner et al. 2000). Here, we tested the concept of 

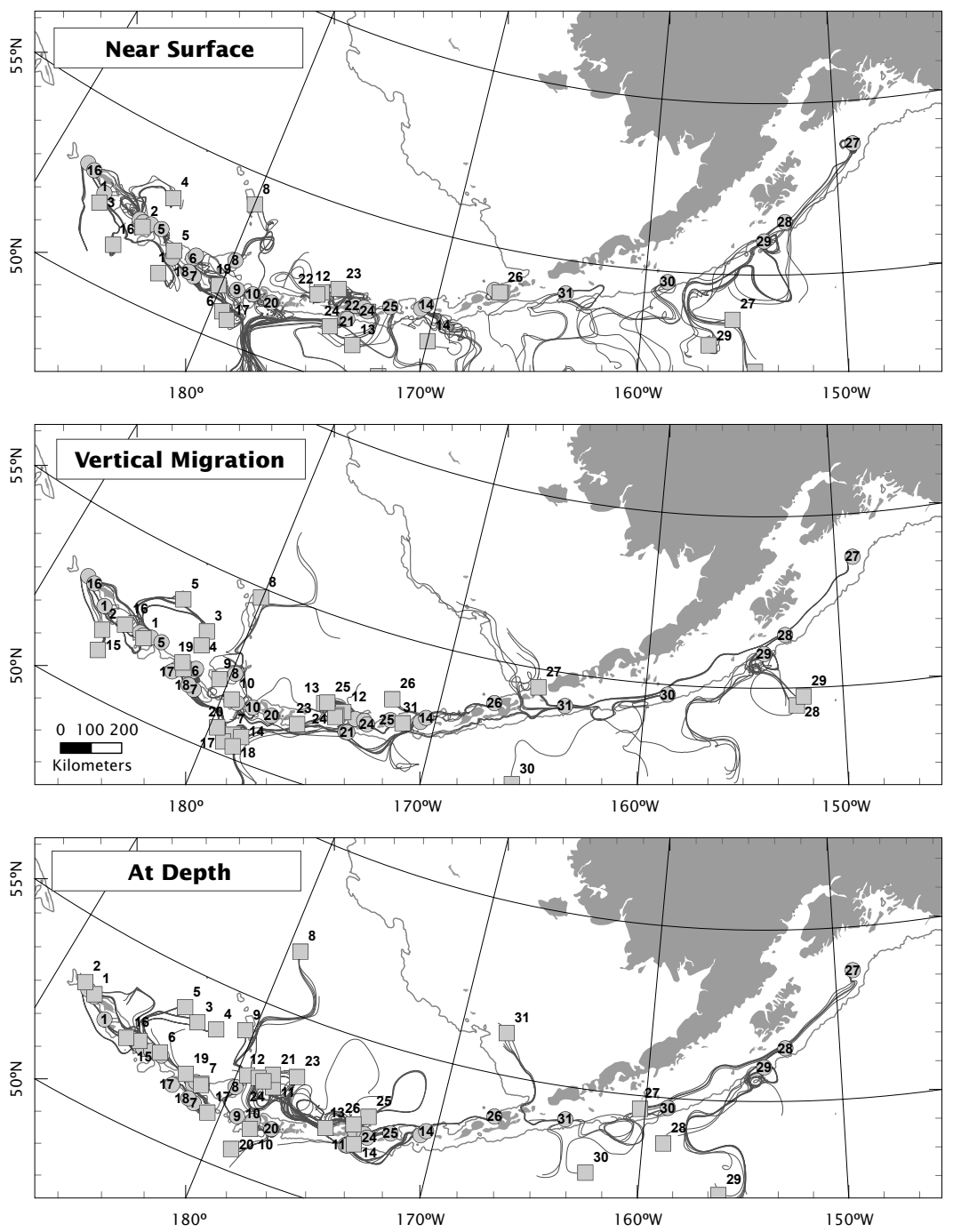

Figure 5. Sample IBM tracks for larvae released on April 1, 1998. Numbered circles denote release locations; numbered squares denote final location of one track from the corresponding release location. The $\mathbf{5 0 0} \mathbf{m}$ isobath is also shown. 

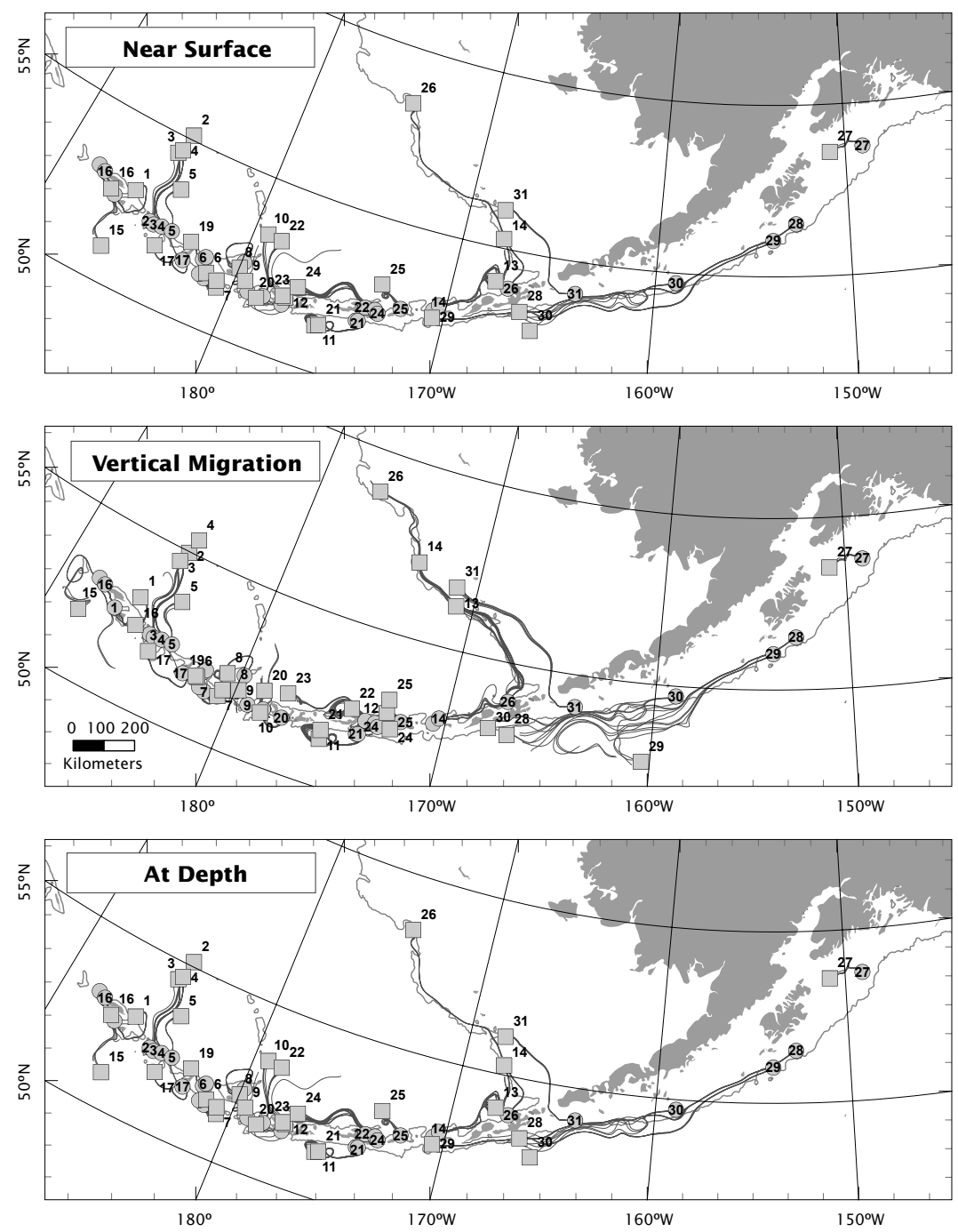

Figure 6. Sample IBM tracks for larvae released on June 1, 1998. Numbered circles denote release locations; numbered squares denote final location of one track from the corresponding release location. The $500 \mathrm{~m}$ isobath is also shown. 

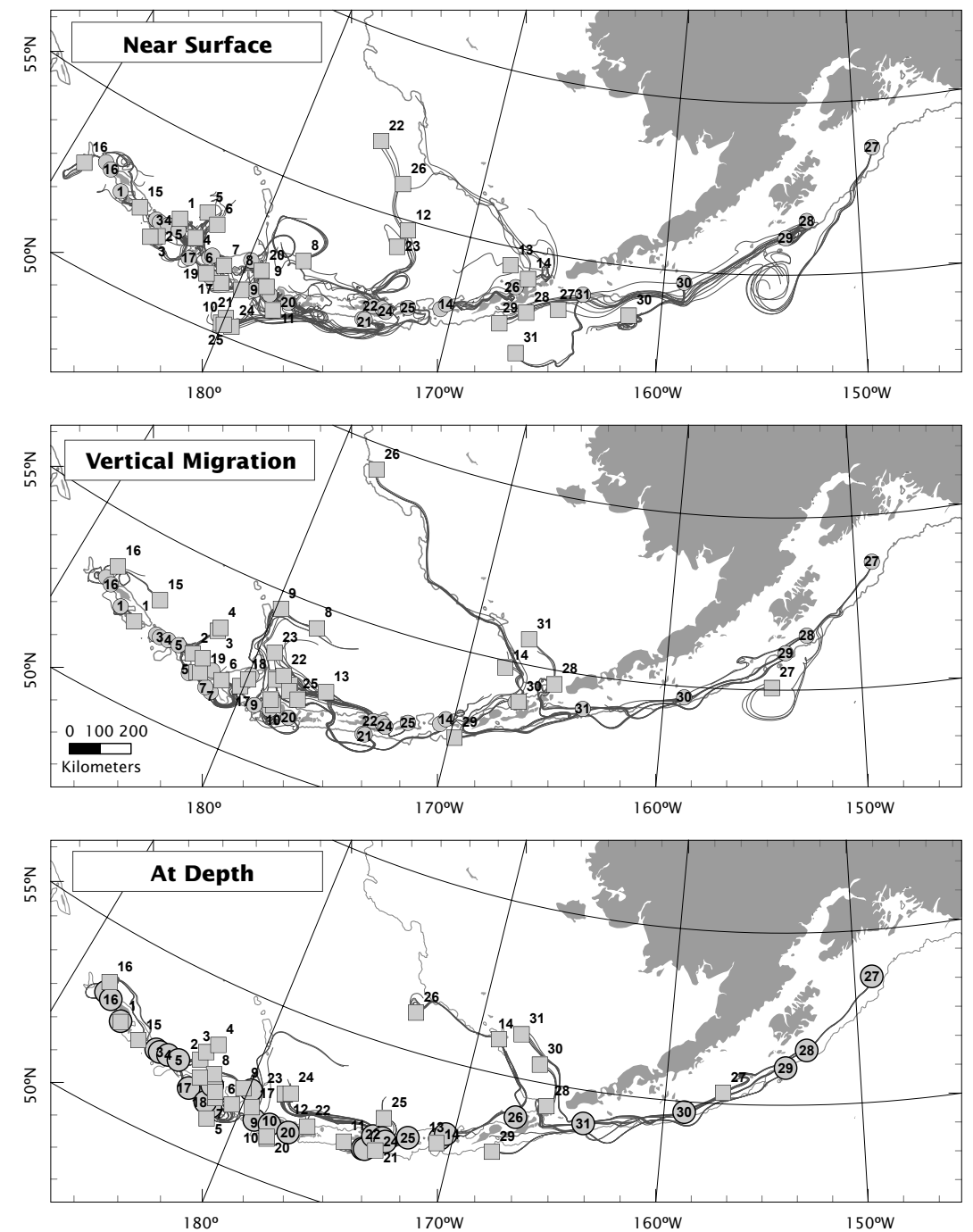

Figure 7. Sample IBM track larvae released on April 1, 2001. Numbered circles denote release locations; numbered squares denote final location of one track from the corresponding release location. The $500 \mathrm{~m}$ isobath is also shown. 

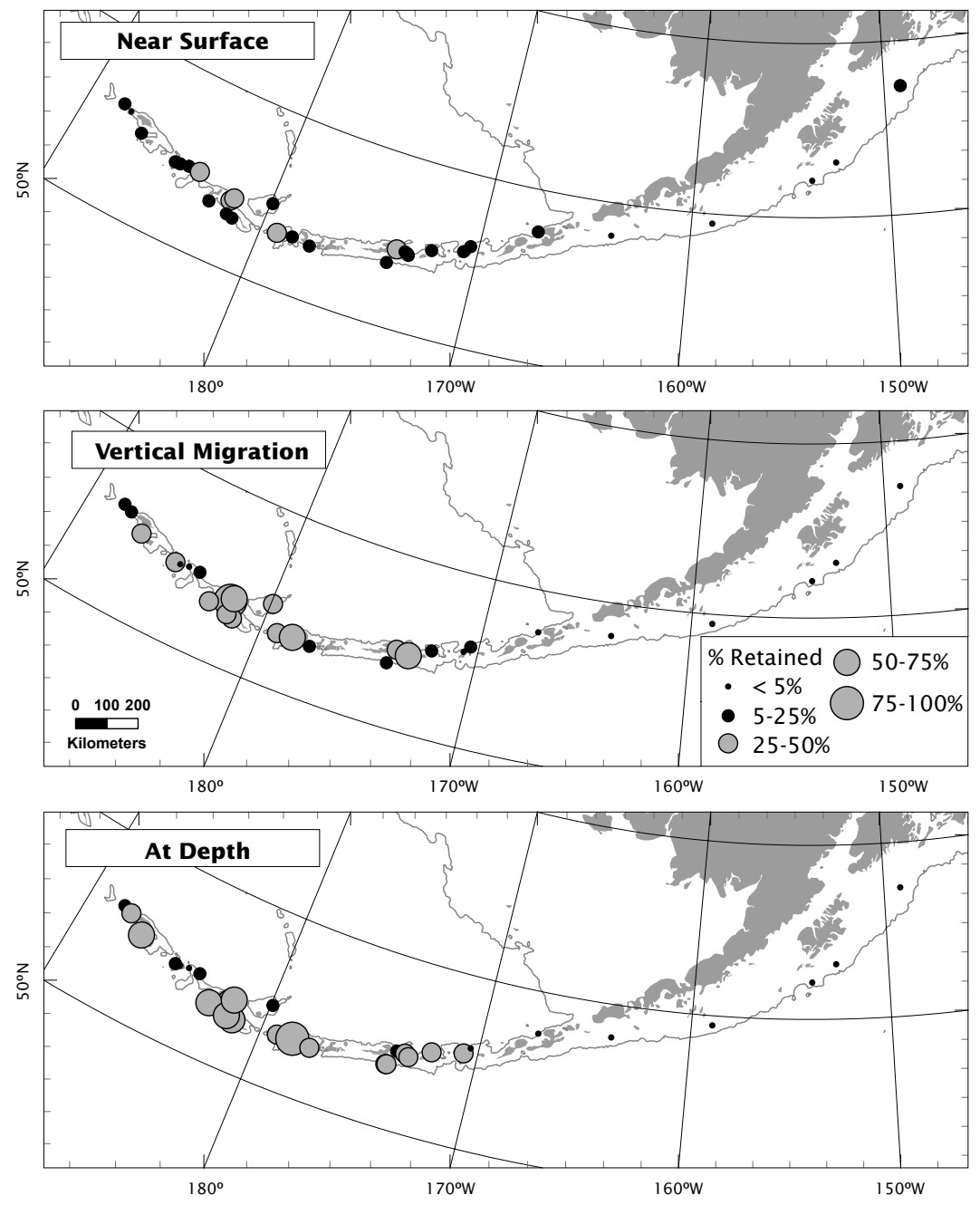

Figure 8. The fraction of larvae retained at each site for the three larval behavior scenarios considered. The retained fraction is calculated over all model year and month combinations. The $500 \mathrm{~m}$ isobath is also shown. 
using models of larval behavior coupled with an oceanographic current model of the northeast Pacific to evaluate potential reserve locations in the AI and GOA. These sites were selected on the basis of historic patterns of adult abundance of several rockfish species (northern rockfish in the GOA; POP, shortraker and rougheye in the AI). Our model results indicated that, over the range of larval behaviors, parturition times, and years we considered, local retention of simulated larvae was greatest in the western AI and essentially negligible in the GOA.

The greater retention within the AI was apparently due to the existence of numerous small-scale $(<100 \mathrm{~km})$ eddies and gyres in that area in all of our hydrodynamic scenarios. Larvae became entrained in these eddies and were not dispersed far from their release sites. A secondary mechanism also contributed to the greater degree of retention in the AI. The Aleutian North Slope Current (flowing eastward) and the Alaskan Stream (flowing westward) serve as oppositely directed currents on opposite sides of the Aleutian chain. Larvae that are swept along the island chain in one direction by one of these currents may "reverse course" simply by being advected through one of the island passes to the other side of the island chain where they would be entrained in the reverse-flowing current. While this mechanism accounted for some larvae in the AI returning to near their release locations, the mechanism for the majority of those retained was entrainment in an eddy or gyre.

Although gyres were also evident in the GOA, their spatial scales were larger $(>200 \mathrm{~km})$ and they tended to be advected to the southwest by the Alaskan Stream, whereas gyres in the AI exhibited little tendency to drift. Thus, entrainment of larvae in a gyre in the GOA was no guarantee of retention. However, if larvae were not entrained in a gyre, they were certain not to be retained near their release site; rather, they were swept far downstream by the ACC and the Alaskan Stream toward the AI.

Although we have probably not captured the true range of interannual variability in larval dispersal with our simulations (only two years were simulated), our results suggest that the high abundances of adult northern rockfish caught by the fishery in the central and western GOA (sites 27-31, Fig. 1; Clausen and Heifetz 2002) may not be part of local self-sustaining populations spanning 10s to 100s of kilometers, but rather may be part of a much more extended population spanning hundreds to thousands of kilometers. Larval dispersal appears to be on the order of $1,000 \mathrm{~km}$ west along the Alaska Peninsula, and possibly into the Aleutians. An eastward contranatant migration by juveniles and subadults is one mechanism that could replenish adult abundances in the central GOA. An alternative mechanism is seeding by recruits from sub-stocks farther to the east in the GOA than those we have modeled (but this, of course, simply raises the issue of how these easterly stocks are maintained). Unfortunately, little information currently exists to 
test either of these hypotheses. It is clear, however, that under either hypothesis the issue of local retention is moot and reserve design must focus on creation of a network of reserves connected by recruitment over large spatial scales.

In terms of reserve design, we note that our results address the issue of larval retention while the design criterion we selected to emphasize addressed the issue of self-sustaining recruitment. Measures of larval retention are relative-and probably nonlinear-indices of self-recruitment. The level of larval retention that corresponds to a self-sustaining level of recruitment is unknown without modeling the dynamics of subsequent life history stages. For the purpose of selecting among otherwise equivalent reserve sites, higher larval retention may be presumed to indicate higher self-recruitment-and thus to indicate areas that would be more likely to support self-sustaining local populations in the absence of outside recruitment. However, other life history factors (e.g., quality and quantity of nursery habitat) may alter the relationship between retention and self-recruitment by altering survival rates on a site-specific basis. Thus, the degree of larval retention alone may be a misleading index of self-recruitment among sites of varying quality. Rather, reserve selection criteria should also include factors that are related to subsequent survival to the reproductive adult stage, such as habitat quality.

Our retention results can certainly be criticized on a number of grounds, and we regard them simply as a test-of-concept at this point. Most significantly, the definition of "retention" used to evaluate parturition sites was rather arbitrary: a simulated larva that was within $50 \mathrm{~km}$ of its parturition site at some time after 30 model days was regarded as being retained near the site. This definition reflected two considerations, the first was that extruded larvae are not immediately capable of transition to a benthic existence and must undergo development in the plankton for some minimum time period. We chose a minimum developmental period of 30 model days, based on rockfish larval durations that are generally assumed to be 1-2 months (Matarese et al. 2003). The second consideration was that older larvae and early juveniles are typically capable of sustained swimming and may be capable of orientation toward nursery habitats. Thus, settlement-competent larvae need only be "close" to natal locations in order to recruit to the local population. We chose $50 \mathrm{~km}$ as a reasonable distance. As a check on the sensitivity of our results, we re-analyzed our model results using two alternative criteria: (1) 45 days and $50 \mathrm{~km}$, and (2) 30 days and $25 \mathrm{~km}$. As one would expect, retention rates declined at most sites under the two alternative criteria (they could not increase). The five sites exhibiting the highest retention were generally consistent across the criteria for the VM and AD behavioral scenarios, but were less so for the NS scenario. 
The characterization of retention for rockfish is somewhat complicated beyond mere distance of dispersal from a parturition site, though. Many rockfish utilize nursery habitats that are not coincident with adult habitats; nursery habitats tend to be inshore of and shallower than adult habitats, being linked by an ontogenetic shift to deeper water (Love et al. 2002). Our use of a $50 \mathrm{~km}$ distance implies that suitable nursery habitat is located within $50 \mathrm{~km}$ of each parturition site. This may be true at most sites in the AI, given the narrow width of the continental shelf there, but may not be true at sites in the GOA, given its much wider shelf. Ideally, it would be better to characterize local retention using the geographic coverage of nursery habitats that are connected to a given parturition site through ontogenetic migration rather than using a simple distance from the parturition site. This is not currently feasible for the AI and GOA, however, because little information exists regarding the location of nursery habitats there.

Another criticism of the retention results is that they are only based on two years of simulated currents. Given the intermittent nature of rockfish recruitment, the temporal coverage used to evaluate sites should include a much wider range of years to incorporate more realistic temporal variability in the current fields and improve confidence in the robustness of the model results. Output from the NEP hydrodynamic model for the period 1958-2004 will be available sometime in 2007 to allow us to address this particular issue.

Finally, we considered retention only from the perspective of individual locations, not as a potential network of sites. Considering the sites as a network of potential marine reserve locations would allow for inter-site connections through larval dispersal; consequently retention within the network would be greater than retention at any single site.

Our models can also be criticized from a number of perspectives, including inadequacy of the hydrodynamic model current fields and lack of biological realism. The most significant inadequacy in the hydrodynamic model was the lack of tidal forcing. Tidal forcing was not included in the hydrodynamic model to reduce computational $(\times 2)$ and storage $(\times 24)$ requirements; consequently the interaction between tidal excursions and vertical migration cannot be captured in our simulations. This interaction would have most effect within the passes and channels of the AI and thus may be an important physical transport process missing from our simulations. Tidal currents could be expected to increase horizontal dispersion of larvae that do not vertically migrate, but might provide a retention mechanism for larvae capable of selective tidal stream transport (Forward and Tankersley 2001). Because rockfish larvae do not appear to undergo diel migration (Sakuma et al. 1999, Love et al. 2002), our model results may overestimate retention in the AI. Additionally, because the spatial resolution of the hydrodynamic model grid is $\sim 10 \mathrm{~km}$, smaller-scale bathymetric features that might 
promote retention (e.g., canyon walls) are not adequately resolved by the hydrodynamic model.

From a biological perspective, the simple larval IBM we developed seems adequate to represent what is known of larval rockfish behavior, which principally consists of observations that Sebastes larvae occupy the upper layers of the water column above the pycnocline (e.g., Ahlstrom 1959, Sakuma et al. 1999), although some information on growth rates is also available (e.g., Kendall and Lenarz 1987, Plaza Pasten et al. 2003) that is not captured in the model. While the models of larval behavior we considered are certainly simplistic, even these models are pushing the bounds on what is known of the behavior of larval rockfish in the $\mathrm{AI}$ and GOA-information required to develop more sophisticated models is simply not available at the present time. However, our model only tracked dispersal through the larval stage. For many rockfish species, transition to a less-dispersive demersal life style does not occur at the end of the larval stage. Rather, these species undergo a pelagic juvenile stage during which further dispersal may occur. This stage may last a few weeks to months prior to transition to a more benthic existence. A more complete model of the pelagic dispersal of rockfish would incorporate this stage as well.

So, is modeling larval dispersion a tool for the design of marine reserves for rockfish? We think the results presented here show that such models can certainly inform the reserve design process. However, given the model deficiencies acknowledged above, as well as the uncertainties associated with early life history information for rockfish in the $\mathrm{AI}$ and GOA, the model presented here requires further refinement and validation before it can be useful as such a tool. We also emphasize the need for more information concerning the early life history of rockfish species, particularly those most vulnerable to overexploitation.

\section{Acknowledgments}

We would like to gratefully acknowledge Elizabeth Dobbins (PMEL), Enrique Curchitser (LDEO), Kate Hedstrom (ARSC), and the NOAA Forecast Systems Laboratory for assistance running the hydrodynamic model; and Anne Hollowed (AFSC) for encouraging and supporting this work. We would also like to thank Richard Stanley and two anonymous reviewers for their comments and suggestions. This research is contribution FOCI-0609 to NOAA's Fisheries-Oceanography Coordinated Investigations, contribution no. 2942 of the Pacific Marine Environmental Laboratory, and contribution no. 301 of the Global Ecosystem Dynamics (GLOBEC) program. It is partially funded by the Joint Institute for the Study of the Atmosphere and Ocean (JISAO) under NOAA Cooperative Agreement NA17RJ1232, contribution no. 1323. This project was also supported in part by funds provided by the AFSC Rockfish Working Group. 


\section{References}

Ahlstrom, E.H. 1959. Vertical distribution of pelagic fish eggs and larvae off California and Baja California. U.S. Fish and Wildlife Service, Fish. Bull. 60:107-146.

Barnett, A.M., A.E. Jahn, P.D. Sertic, and W. Watson. 1984. Distribution of ichthyoplankton off San Onofre, California, and methods for sampling very shallow coastal waters. Fish. Bull. U.S. 82:97-111.

Berkeley, S.A., M.A. Hixon, R.J. Larson, and M.S. Love. 2004. Fisheries sustainability via protection of age structure and spatial distribution of fish populations. Fisheries 29(8):23-32.

Boehlert, G.W., D.M. Gadomski, and B.C. Mundy. 1985. Vertical distribution of ichthyoplankton off the Oregon coast in spring and summer months. Fish. Bull. U.S. 83:611-621.

Buonaccorsi, V.P., C.A. Kimbrell, E.A. Lynn, and R.D. Vetter. 2002. Population structure of copper rockfish (Sebastes carinus) reflects postglacial colonization and contemporary patterns of larval dispersal. Can. J. Fish. Aquat. Sci. 59:1374-1384.

Clark, W.G. 2002. $F_{35 \%}$ revisited 10 years later. N. Am. J. Fish. Manag. 22:251-257.

Clausen, D.M., and J. Heifetz. 2002. The northern rockfish, Sebastes polyspinis, in Alaska: Commercial fishery, distribution, and biology. Mar. Fish. Rev. 64(4):1-18.

Curchitser, E.N., D.B. Haidvogel, A.J. Hermann, E.L. Dobbins, and T.M. Powell. 2005. Multi-scale modeling of the North Pacific Ocean I: Assessment and analysis of simulated basin-scale variability (1996-2003). J. Geophys. Res. 110, C11021, doi: 10.1029/2005/2005JC002902.

Dorn, M.W. 2002. Advice on West Coast rockfish harvest rates from Bayesian meta-analysis of stock-recruit relationships. N. Am. J. Fish. Manag. 22:280-300.

Doyle, M.J., K.L. Mier, M.S. Busby, and R.D. Brodeur. 2002. Regional variation in springtime ichthyoplankton assemblages in the northeast Pacific Ocean. Prog. Oceanogr. 53:247-281.

Fairall, C.W., E.F. Bradley, D.P. Rogers, J.B. Edson, and G.S. Young. 1996. Bulk parameterization of air-sea fluxes for Tropical Ocean-Global Atmosphere Coupled-Ocean Atmosphere Response Experiment. J. Geophys. Res. 101(C2):1295-1308.

Forward, R.B., and R.A. Tankersley. 2001. Selective tidal-stream transport of marine animals. Oceanogr. Mar. Biol. Ann. Rev. 39:305-353.

Haidvogel, D.B., H.G. Arango, K. Hedstrom, A. Beckmann, P. Malanotte-Rizzoli, and A.F. Shchepetkin. 2000. Model evaluation experiments in the North Atlantic Basin: Simulations in nonlinear terrain-following coordinates. Dyn. Atmos. Oceans 32:239-281. 
Hanselman, D., J. Heifetz, J.T. Fujioka, and J.N. Ianelli. 2005. Gulf of Alaska Pacific ocean perch. In: Stock assessment and fishery evaluation report for the 2005 Gulf of Alaska groundfish fishery. North Pacific Fishery Management Council, Anchorage, Alaska, pp. 525-578.

Heifetz, J., J.N. Ianelli, D.M. Clausen, and J.T. Fujioka. 1999. Slope rockfish. In: Stock assessment and fishery evaluation report for the 2000 Gulf of Alaska groundfish fishery. North Pacific Fishery Management Council, Anchorage, Alaska, pp. 6-1 to 6-49.

Hunt, G.L., and P.J. Stabeno. 2005. Oceanography and ecology of the Aleutian archipelago: Spatial and temporal variation. Fish. Oceanogr. 14(S1):292-306.

Ianelli, J.N. 2002. Simulation analyses testing the robustness of productivity determination from West Coast Pacific ocean perch stock assessment data. N. Am. J. Fish. Manag. 22:301-310.

Ito, D.H., P.D. Spencer, and J.N. Ianelli. 1999. Pacific ocean perch. In: Stock assessment and fishery evaluation report for the 2000 Bering Sea and Aleutian Islands groundfish fishery. North Pacific Fishery Management Council, Anchorage, Alaska, pp. 519-557.

Kendall, A.W., and W.H. Lenarz. 1987. Status of early life history studies of northeast Pacific rockfishes. In: Proceedings of the International Rockfish Symposium. Alaska Sea Grant, University of Alaska Fairbanks, pp. 99-128.

Ladd, C., G.L. Hunt Jr., C.W. Mordy, S.A. Salo, and P.J. Stabeno. 2005. Marine environment of the eastern and central Aleutian Islands. Fish. Oceanogr. 14(S1):22-38.

Laidig, T.E., S. Ralston, and J.R. Bence. 1991. Dynamics of growth in the early life history of shortbelly rockfish Sebastes jordani. Fish. Bull. U.S. 89:611-621.

Large, W.G., J.C. McWilliams, and S.C. Doney. 1994. Oceanic vertical mixing: A review and a model with a nonlocal boundary layer parameterization. Rev. Geophysics. 32:363-404.

Love, M.S., M. Yoklavich, and L. Thorsteinson. 2002. The rockfishes of the Northeast Pacific. University of California Press, Los Angeles. 404 pp.

Lyubimova, T.G. 1965. Main stages in the life cycle of the rockfish Sebastodes alutus (Gilbert) in the Gulf of Alaska. Trudy VNIRO 49:85-111.

Marchesiello, P., J.C. McWilliams, and A.F. Shchepetkin. 2001. Open boundary conditions for long-term integration of regional ocean models. Ocean Model. 3:1-20.

Matala, A.P., A.K. Gray, J. Heifetz, and A.J. Gharrett. 2004. Population structure of Alaskan shortraker rockfish, Sebastes borealis, inferred from microsatellite variation. Environ. Biol. Fishes 69:201-210.

Matarese, A.C., D.M. Blood, S.J. Piquelle, and J.L. Benson. 2003. Atlas of abundance and distribution patterns of ichthyoplankton from the northeast Pacific Ocean and Bering Sea ecosystems based on research conducted by the Alaska Fisheries Science Center (1972-1996). NOAA Prof. Paper NMFS 1. $281 \mathrm{pp}$. 
Moore, A.M., H.G. Arango, E. Di Lorenzo, B.D. Cornuelle, A.J. Miller, and D.J. Neilson. 2004. A comprehensive ocean prediction and analysis system based on the tangent linear and adjoint of a regional ocean model. Ocean Model. 7:227-258.

Moser, H.G., and G.W. Boehlert. 1991. Ecology of pelagic larvae and juveniles of the genus Sebastes. Environ. Biol. Fish. 30:203-224.

Murray, S.N., R.F. Ambrose, J.A. Bohnsack, L.W. Botsford, M.H. Carr, G.E. Davis, P.K. Dayton, D. Gotshall, D.R. Gunderson, M.A. Hixon, J. Lubchenco, M. Mangel, A. MacCall, D.A. McArdle, J.C. Ogden, J. Roughgarden, R.M. Starr, M.J. Tegner, and M.M. Yoklavich. 1999. No-take reserve networks: Sustaining fishery populations and marine ecosystems. Fisheries 24(11):11-25.

Neilson, J.D., and R.I. Perry. 1990. Diel vertical migrations of marine fishes: An obligate or facultative process? Adv. Mar. Biol. 26:115-168.

NPFMC. 2004a. Stock assessment and fishery evaluation report for the 2004 Bering Sea and Aleutian Islands groundfish fishery. North Pacific Fishery Management Council, Anchorage, Alaska. 1094 pp.

NPFMC. 2004b. Stock assessment and fishery evaluation report for the 2004 Gulf of Alaska groundfish fishery. North Pacific Fishery Management Council, Anchorage, Alaska. 538 pp.

O'Connell, V., W.W. Wakefield, and H.G. Greene. 1998. The use of a no-take marine reserve in the eastern Gulf of Alaska to protect essential fish habitat. In: M. Yoklavich (ed.), Marine Harvest Refugia for West Coast Rockfish: A Workshop. NOAA-TM-NMFS-SWFSC-255, La Jolla, California, pp. 125-132.

Plaza Pasten, G., S. Katayama, and M. Omori. 2003. Timing of parturition, planktonic duration, and settlement patterns of the black rockfish, Sebastes inermis. Environ. Biol. Fishes 68:229-239.

Ralston, S., and D.F. Howard. 1995. On the development of year-class strength and cohort variability in two northern California rockfishes. Fish. Bull. U.S. 93:710-720.

Reed, R.K., and P.J. Stabeno. 1989. Recent observations of variability in the path and vertical structure of the Alaskan Stream. J. Phys. Oceanogr. 19:1634-1642.

Reuter, R., and P.D. Spencer. 2007. Characterizing aspects of rockfish (Sebastes spp.) assemblages in the Aleutian Islands, Alaska. In: J. Heifetz, J. DiCosimo, A.J. Gharrett, M.S. Love, V.M. O'Connell, and R.D. Stanley (eds.), Biology, assessment, and management of North Pacific rockfishes. Alaska Sea Grant, University of Alaska Fairbanks. (This volume.)

Roberts, C.M. 2000. Selecting marine reserve locations: Optimality versus opportunism. Bull. Mar. Sci. 66:581-592.

Sakuma, K.M., and T.E. Laidig. 1995. Description of larval and pelagic juvenile chilipepper, Sebastes goodei (family Scorpaenidae), with an examination of larval growth. Fish. Bull. U.S. 93:721-731.

Sakuma, K.M., S. Ralston, and D.A. Roberts. 1999. Diel vertical distribution of postflexion larval Citharichthys spp. and Sebastes spp. off central California. Fish. Oceanogr. 8:68-76. 
Shchepetkin, A.F., and J.C. McWilliams. 2005. The Regional Ocean Modeling System: A split-explicit, free-surface, topography-following coordinate ocean model. Ocean Model. 9:347-404.

Shenker, J.M. 1988. Oceanographic associations of neustonic larval and juvenile fishes and Dungeness crab megalopae off Oregon. Fish. Bull. U.S. 86:299-317.

Soh, S., D.R. Gunderson, and D.H. Ito. 2001. The potential role of marine reserves in the management of shortraker rockfish (Sebastes borealis) and rougheye rockfish (S. aleutianus) in the Gulf of Alaska. Fish. Bull. U.S. 99:168-179.

Spencer P.D., J.N. Ianelli, and H. Zenger. 2005. Pacific ocean perch. In: Stock assessment and fishery evaluation report for the 2005 Bering Sea and Aleutian Islands groundfish fishery. North Pacific Fishery Management Council, Anchorage, Alaska, pp. 675-746.

Stabeno, P.J., and R.K. Reed. 1994. Circulation in the Bering Sea basin observed by satellite-tracked drifters: 1986-1993. J. Phys. Oceanogr. 24:848-854.

Stabeno, P.J., R.K. Reed, and J.D. Schumacher. 1995. The Alaska Coastal Current: Continuity of transport and forcing. J. Geophys. Res. 100(C2):2477-2485.

Stabeno, P.J., D.G. Kachel, N.B. Kachel, and M.E. Sullivan. 2005. Observations from moorings in the Aleutian passes: Temperature, salinity and transport. Fish. Oceanogr. 14(S1):39-54.

Stabeno, P.J., N.A. Bond, A.J. Hermann, N.B. Kachel, C.W. Mordy, and J.E. Overland. 2004. Meteorology and oceanography of the Northern Gulf of Alaska. Cont. Shelf Res. 24:859-897.

Styles, R., and S.M. Glenn. 2000. Modeling stratified combined wave-current bottom boundary layers. J. Geophys. Res. 101:24119-24139.

Ware, D.M., and G.A. McFarlane. 1989. Fisheries production domains in the northeast Pacific Ocean. In: R.J. Beamish and G.A. McFarlane (eds.), Effects of ocean variability and an evaluation of parameters used in stock assessment models. Can. Spec. Publ. Fish. Aquat. Sci. 108:359-379.

Warner, R.R., S.E. Swearer, and J.E. Casselle. 2000. Larval accumulation and retention: Implications for the design of marine reserves and essential habitat. Bull. Mar. Sci. 66:821-830.

Westrheim, S.J. 1975. Reproduction, maturation, and identification of larvae of some Sebastes (Scorpaenidae) species in the northeast Pacific Ocean. J. Fish. Res. Board Can. 32:2399-2411.

Withler, R.E., T.D. Beacham, A.D. Schulze, L.J. Richards, and K.M. Miller. 2001. Co-existing populations of Pacific ocean perch, Sebastes alutus, in Queen Charlotte Sound, British Columbia. Mar. Biol. 139:1-12.

Wyllie Echeverria, T. 1987. Thirty-four species of California rockfishes: Maturity and seasonality of reproduction. Fish. Bull. U.S. 85:229-250. 
